\title{
Experimental contribution to the study of the physic-mechanical behavior and durability of high-performance concretes based on ternary binder (cement, silica fume and granulated blast furnace slag)
}

\author{
Ouahab Rahim, Djamel Achoura \\ Materials, Geomaterials and Environment Laboratory, Department of Civil Engineering, Badji Mokbtar-Annaba University, P. \\ O. Box 12, 23000 Annaba, Algeria \\ ouabab.rabim@univ-annaba.org,achoudj@yahoo.fr
}

Mohammed Benzerara

Materials, Geomaterials and Environment Laboratory, Department of Civil Engineering, Badji Mokbtar-Annaba University, $P$. O. Box 12, 23000 Annaba, Algeria

Université Bretagne-Sud, UMR CNRS 6027, IRDL, F-56100 Lorient, France

mohammed.benzerara@univ-annaba.org,mohammed.benzerara@univ-ubs.fr

Céline Bascoulès-Perlot

Université de Pau et des Pays de l'Adour/E2S UPPA, Laboratoire des Sciences de l'Ingénieur Appliquées à la Mécanique et au Génie Electrique SLAME-IPRA, EA4581, 64600, Anglet, France

celine.bascoules@univ-pau.fr

ABSTRACT. High performance concrete (HPC) is an innovative concrete used widely in modern construction. New techniques of formulating and designing HPC have made it possible to obtain remarkable mechanical performance and durability compared to the conventional concrete. The main advantages of HPC are related to its low porosity, very high mechanical resistance, and excellent durability. The ease of HPC application is obtained by the combined use of superplasticizer and mineral addition, which results in a significant increase in the compressive strength while improving workability and durability.

The Algerian steel industry in North Africa generates very large quantities of slag which are currently little or not used for the formulation of hydraulic binders in the field of construction materials. In the current economic climate, research on high-performance concretes in Algeria is mainly focused on their formulations with a view to producing cement-based concretes composed of better strengths and more durable.

The objective of this work is to optimize a formulation of HPC based on a ternary binder integrating granulated Algerian blast furnace slag as a cement substitute. This can partially solve an environmental problem by recycling

\section{OPEN ACCESS}

Citation: Rahim, O., Achoura, D., Benzerara, M., Bascoulès-Perlot, C., Experimental contribution to the study of the physicmechanical behavior and durability of highperformance concretes based on ternary binder (cement, silica fume and granulated blast furnace slag), Frattura ed Integrità Strutturale, 59 (2022) 344-358.

Received: 09.08.2021

Accepted: 10.11.2021

Published: 01.01.2022

Copyright: (C) 2022 This is an open access article under the terms of the CC-BY 4.0, which permits unrestricted use, distribution, and reproduction in any medium, provided the original author and source are credited. 
waste and by-products from the steel industry. The manufacture of a HPC with less cement could lead to both environmental benefits thanks to a reduction in $\mathrm{CO}_{2}$ emissions and financial benefits through a lower construction cost and build more sustainable structures.

KEYWORDS. High performance concrete; Granulated blast furnace slag; Ternary binders; Mechanical behaviors; Durability; Environment.

\section{INTRODUCTION}

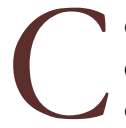

oncrete is the most widely used construction material in the world [1-3], and many types of concrete have been developed in recent years [4-7]. High performance concrete (HPC) has also been widely used in recent years because of its superior mechanical properties and excellent durability performance. By the use of the new generation of superplasticizer and the addition of mineral, the new types of HPC have a denser microstructure with very low permeability. This improves workability, increases mechanical resistance $(>60 \mathrm{MPa})$, provides increased resistance to the physicochemical attacks, and therefore improves the performance under extreme stresses and the durability under harsh environmental conditions [8-11].

The general principle for the formulation of HPC involves the improvement of compactness. This is achieved primarily by lowering the $\mathrm{W} / \mathrm{C}$ ratio by a superplasticizer and adjusting the granular extent by adding ultra-fine minerals. These fillers play a dual role in concrete by increasing the compactness by filling micro-pores, on the one hand, and on the other hand providing chemical reactions with the other materials, which participate in the formation of secondary hydrates and consequently improves the resistance and durability [12].

HPCs are characterized by a marked improvement in durability performance, resulting from extremely reduced porosity. Indeed, the high compactness gives them a low permeability that opposes the transfer of aggressive agents in liquid or gas phase in their mass [13].

HPCs which, are simply known as low Water/Cement or Water/Lian ratios concretes, are also economical concretes from the point of view of the initial cost because it is possible to build an equivalent structure with less formwork, less concrete to be placed and less reinforcements [14,15].

Although several research works have been carried out on HPC durability, this work is essentially focused on basic constituents (binder, aggregate, and superplasticizer), and in particular mineral additions. The use of a ternary binder (cement, silica fume, and granulated slag) is one of the recent areas of research, which aims to improve HPC durability and mechanical behavior, and minimize the negative environmental impacts.

Cementitious materials made of ternary binders can in fact exhibit superior performance to those based on binary binders in terms of heat release, mechanical resistance at early ages, and durability [16,17].

Several research studies have reported that the incorporation of silica fume combined with other mineral additions (pozzolan, blast furnace slag, or fly ash) in the cement matrix improves the mechanical properties and the durability of HPC $[18,19]$.

Nowadays, reducing the environmental impacts of waste materials such as slag and fly ash is inevitable and must go through innovative constructive solutions. Development of different concretes based on binary or ternary binders composed of waste materials other than clinker, such as blast furnace slag or fly ash, etc., not only ensures mechanical performance and proper durability in the short and long term but also provides ecological and economic benefits [20].

The incorporation of industrial by-products in the form of mineral additions in concrete makes it possible to reduce the consumption of cement and therefore reduce e $\mathrm{CO}_{2}$ emissions, which presents a significant environmental advantage [21]. The granulated slag, as a fine-grained powder, possess several interesting properties such as chemical composition which is close to that of cement, regularity of composition for the same production source and latent reactivity activated in the presence of Portland cement. Granulated slag is an additive commonly used in the manufacturing of different types of cements [22-24].

The properties of ground granulated blast furnace slag, specifically its low water absorption rate by the smooth surfaces of the granulated slag grains, work together to improve the workability of HPC over ordinary Portland cement concrete [22,2527]. 
Silica fume and superplasticizer are the basic and necessary components in the formulation of an HPC. They significantly contribute to improving the mechanical strength and durability. Their effects on the physical and chemical properties of concrete are due to the filling mechanism and chemical reactions in concrete. Thus, the difference in particle size of the silica fume and cement contributes to the intensification of the paste through the physical effect of the filler type, which leads to more compaction and accumulation of the solid grains [15].

This research work falls within the framework of concern to take into account and protect the environment, natural resources and to fight against pollution leads to a new behavior. To this environmental concern is obviously linked an economic aspect of the use of waste and local by-products in the construction sector in North Africa. Algeria has a steel industry, which generates a significant amount of this waste and by-products. High performance concretes have very satisfactory intrinsic mechanical characteristics. However, several questions remain unanswered, particularly with regard to the use of a high dosage of cement without additions, the manufacture of which is associated with a high emission of $\mathrm{CO}_{2}$. To overcome this environmental and economic problem, one of the solutions that can be considered is the use of granulated blast furnace slag as a partial replacement for Portland cement.

The objective of this work is to optimize a formulation of HPC based on a ternary binder integrating the granulated blast furnace slag from the steel complex of El-Hadjar Annaba (North-East of Algeria), which presents a slow reactivity, as a substitute for cement in order to improve its durability and its long-term mechanical performance. The experimental work presents a study of the influence of the substitution of Portland cement by granulated slag, for a fixed dosage in silica fume, on the physico-mechanical behavior and the durability of HPC.

\section{MATERIALS AND METHODS}

\section{Materials}

7 he mechanical properties and durability of high performance concretes depend mainly on the quality of their constituents. The analysis of each constituent allows optimizing the amount of raw materials used in HPCs. The main constituents related to the formulation of HPCs are raw materials.

\section{Cement}

The cement used in this study is an Algerian cement (CPA-CEM I / $42.5 \mathrm{~N}$ ) (NF EN197-1) from a single delivery from the cement plant (Biskria Ciment SPA) in the town of Biskra, Algeria. The chemical and mineralogical compositions are given in Tabs. 1 and 2 respectively.

\begin{tabular}{cccccccccc}
\hline Elements & $\mathrm{CaO}$ & $\mathrm{SiO}_{2}$ & $\mathrm{Fe}_{2} \mathrm{O}_{3}$ & $\mathrm{Al}_{2} \mathrm{O}_{3}$ & $\mathrm{~K}_{2} \mathrm{O}$ & $\mathrm{MgO}$ & $\mathrm{SO}_{3}$ & $\mathrm{Cl}$ & P.A.F \\
Content $(\%)$ & 57.45 & 18.25 & 3.02 & 4.79 & 0.51 & 2.00 & 3.88 & 0.006 & - \\
\hline
\end{tabular}

Table 1: Chemical compositions of cement.

\begin{tabular}{ccc}
\hline Normal consistency & Absolute density $\left(\mathrm{g} / \mathrm{cm}^{3}\right)$ & Blaine Specific Surface $\left(\mathrm{cm}^{2} / \mathrm{g}\right)$ \\
26 & 3.1 & 3900 \\
\hline
\end{tabular}

Table 2: Physical characteristics of cement.

\section{Ground granulated blast furnace slag}

The ground granulated blast furnace slag used is a by-product of the manufacturing of cast iron in Steel Complex of ElHadjar Annaba, Algeria. It was obtained in the form of coarse-grained powder, and by grinding in the laboratory, with a granular extent of $<80 \mu \mathrm{m}$. (Standard XP P 18-540). The chemical compositions and physical characteristics of the ground granulated blast furnace slag are shown in Tabs. 3 and 4 respectively.

\begin{tabular}{ccccccccccc}
\hline $\begin{array}{c}\text { Elements } \\
\begin{array}{c}\text { Content } \\
(\%)\end{array}\end{array}$ & $\mathrm{CaO}$ & $\mathrm{SiO}_{2}$ & $\mathrm{Fe}_{2} \mathrm{O}_{3}$ & $\mathrm{Al}_{2} \mathrm{O}_{3}$ & $\mathrm{~K}_{2} \mathrm{O}$ & $\mathrm{Na}_{2} \mathrm{O}$ & $\mathrm{MgO}$ & $\mathrm{SO}_{3}$ & $\mathrm{Cl}$ & P.A.F \\
\hline
\end{tabular}

Table 3: Chemical compositions of ground granulated blast furnace slag. 


\begin{tabular}{ccc}
\hline Absolute density $\left(\mathrm{g} / \mathrm{cm}^{3}\right)$ & Apparent volumetric mass $\left(\mathrm{g} / \mathrm{cm}^{3}\right)$ & Blaine Specific Surface $\left(\mathrm{cm}^{2} / \mathrm{g}\right)$ \\
2.89 & 1.19 & 4800 \\
\hline
\end{tabular}

Table 4: Physical characteristics of ground granulated blast furnace slag.

\section{Silica fume}

The silica fume used in this work was a very fine-grained powder of grey color supplied by the GRANITEX Company in Algeria. The average grain diameter of the used silica fume was around $0.1 \mu \mathrm{m}$. The chemical composition and physical characteristics of silica fume are shown in Tabs. 5 and 6 respectively.

\begin{tabular}{ccccccccccc}
\hline $\begin{array}{c}\text { Elements } \\
\begin{array}{c}\text { Content } \\
(\%)\end{array}\end{array}$ & $\mathrm{CaO}$ & $\mathrm{SiO}_{2}$ & $\mathrm{Fe}_{2} \mathrm{O}_{3}$ & $\mathrm{Al}_{2} \mathrm{O}_{3}$ & $\mathrm{~K}_{2} \mathrm{O}$ & $\mathrm{Na}_{2} \mathrm{O}$ & $\mathrm{MgO}$ & $\mathrm{SO}_{3}$ & $\mathrm{Cl}^{-}$ & P.A.F \\
\hline
\end{tabular}

Table 5: Chemical compositions of silica fume.

\begin{tabular}{ccc}
\hline Absolute density $\left(\mathrm{g} / \mathrm{cm}^{3}\right)$ & Apparent volumetric mass $\left(\mathrm{g} / \mathrm{cm}^{3}\right)$ & Blaine Specific Surface $\left(\mathrm{cm}^{2} / \mathrm{g}\right)$ \\
2.24 & 0.5 & 5000 \\
\hline
\end{tabular}

Table 6: Physical characteristics of silica fume.

\section{Aggregates}

In this study, two types of crushed limestone aggregates of granular classes $(3 / 8)$ and $(8 / 15)$ are used from the region of Guelma, Algeria. Two types of sand with different mineralogical nature, from the region of Tebessa, Algeria are used, the first is fine siliceous sand and the second quarried sand. The physical characteristics of the aggregates used are grouped in Tab. 7.

\begin{tabular}{ccccc}
\hline $\begin{array}{c}\text { Characteristics } \\
\text { materials }\end{array}$ & $\begin{array}{c}\text { Absolute } \\
\text { density } \\
\left(\mathrm{g} / \mathrm{cm}^{3}\right)\end{array}$ & $\begin{array}{c}\text { Fineness } \\
\text { modulus } \\
(\%)\end{array}$ & $\begin{array}{c}\text { Sand } \\
\text { equivalent } \\
(\%)\end{array}$ & $\begin{array}{c}\text { Los } \\
\text { Angeles } \\
(\%)\end{array}$ \\
Dune sand & 2.61 & 1.60 & 81.30 & - \\
Quarry sand & 2.55 & 3.93 & 78.92 & - \\
Gravel 8/15 & 2.62 & - & - & 19 \\
Gravel 3/8 & 2.62 & - & - & 21 \\
\hline
\end{tabular}

Table 7: Physical characteristics of aggregates used.

\section{Superplasticizer}

MEDAFLOW- 30 is the super plasticizer chosen in this research. It is a high-range water reducer sourced from GRANITEX. It has a liquid form and a light brown color. It complies with standard NF EN 934-2. Its properties are shown in Tab. 8.

\begin{tabular}{ccccc}
\hline Form & Color & $\mathrm{pH}$ & Density & Chlorine content \\
Liquid & Light brown & $6-6.5$ & $1.07 \pm 0.01$ & $<1 \mathrm{~g} / 1$ \\
\hline
\end{tabular}

Table 8: Property of the GRANITEX MEDAFLOW- 30. 


\section{Mixing water}

The quality of water can also affect the mechanical properties of concrete and cementitious materials [28-32]. According to NFP 18-303, in this study tap (drinking) water was used for preparing the specimens and distilled water was used for the characterization and durability tests [31-35].

\section{Methods - Mix design of HPC}

Two methods were used to optimize the formulation and mix design of HPC. The Dreux-Gorisse method was used to optimize the granular extent, and the HPC formulation approach from the University of Sherbrook [8,36], was followed for the determination of the dosages of various constituents. The optimal composition of the five HPC mixtures is reported in Tab. 9.

\begin{tabular}{|c|c|c|c|c|c|c|}
\hline \multirow[b]{2}{*}{ Constituents } & \multirow[b]{2}{*}{ Unit } & \multicolumn{4}{|c|}{ Concretes } & \multirow[b]{2}{*}{$\begin{array}{l}\text { HPC } \\
50 \% \\
\text { Slag }\end{array}$} \\
\hline & & $\begin{array}{l}\text { Control } \\
\text { HPC }\end{array}$ & $\begin{array}{c}\text { HPC } \\
10 \% \\
\text { Slag }\end{array}$ & $\begin{array}{l}\text { HPC } \\
20 \% \\
\text { Slag }\end{array}$ & $\begin{array}{c}\text { HPC } \\
30 \% \\
\text { Slag }\end{array}$ & \\
\hline Cement & $\mathrm{kg}$ & 524 & 471.60 & 419.20 & 366.80 & 262 \\
\hline Gravel (8/15) & $\mathrm{kg}$ & 856 & 856 & 856 & 856 & 856 \\
\hline Gravel (3/8) & $\mathrm{kg}$ & 194 & 194 & 194 & 194 & 194 \\
\hline $\begin{array}{l}\text { Dune sand } \\
(0 / 2)\end{array}$ & $\mathrm{kg}$ & 331 & 331 & 331 & 331 & 331 \\
\hline $\begin{array}{c}\text { Quarry sand } \\
(0 / 5)\end{array}$ & $\mathrm{kg}$ & 272 & 272 & 272 & 272 & 272 \\
\hline Silica fume & $\mathrm{kg}$ & 58 & 58 & 58 & 58 & 58 \\
\hline Granulated slag & $\mathrm{kg}$ & - & 52.40 & 104.80 & 157.20 & 262 \\
\hline Water & $\mathrm{kg}$ & 160 & 160 & 160 & 160 & 160 \\
\hline Water/Binder & $(\%)$ & 0.27 & 0.27 & 0.27 & 0.27 & 0.27 \\
\hline $\begin{array}{c}\text { Superplasticizer } \\
(2.2 \%)\end{array}$ & $\mathrm{kg}$ & 11.6 & 11.6 & 11.6 & 11.6 & 11.6 \\
\hline
\end{tabular}

Table 9: Mix design and formulation of HPC concretes.

\section{EXPERIMENTAL PROCEDURE}

$\mathrm{T}$

he preparation of the specimens was carried out according to standard NF EN 12390-1. The mixing was carried out using a concrete mixer with a capacity of $30 \mathrm{~L}$. The mixing process took 5 minutes time, and the vibration was performed on a vibrating table with adjustable vibration amplitude.

The Abrams cone test NF EN12350-2 was used to measure the workability of the mixtures. Fig. 1 presents an example of workability test carried out by the Abrams' cone.

After 24 hours of storage in a humid chamber, the demoulded samples were stored in baths filled (saturating humidity) with distilled water $\left(\mathrm{PH}=7, \mathrm{t}=20 \pm{ }^{\circ} \mathrm{C}, \mathrm{RH}=100 \%\right)$.

Mechanical characterization was obtained by measuring the tensile strength bending $7 \times 7 \times 28 \mathrm{~cm}^{3}$ specimens (Fig. 2), and compressive strength was performed on cubic specimens with the dimensions of $10 \times 10 \times 10 \mathrm{~cm}^{3}$ (Fig. 3) according to standard NF EN 12390-5 and NF EN 12390 -3.

Concrete in the hardened state has a porosity, which is due to the presence of pores included in the actual texture of the hydrates and of capillaries, which develop in the structure of the grains. The durability of concrete depends primarily on the difficulty that aggressive agents have in penetrating the porous network of concrete. Porosity is a determining parameter of the durability of concrete; the more the porosity decreases, the more the mechanical properties increase and the more the 
permeability decreases. This is why the tests for water absorption by capillarity, the porosity accessible to water and the gas permeability were carried out to evaluate the porosity of the HPCs studied.

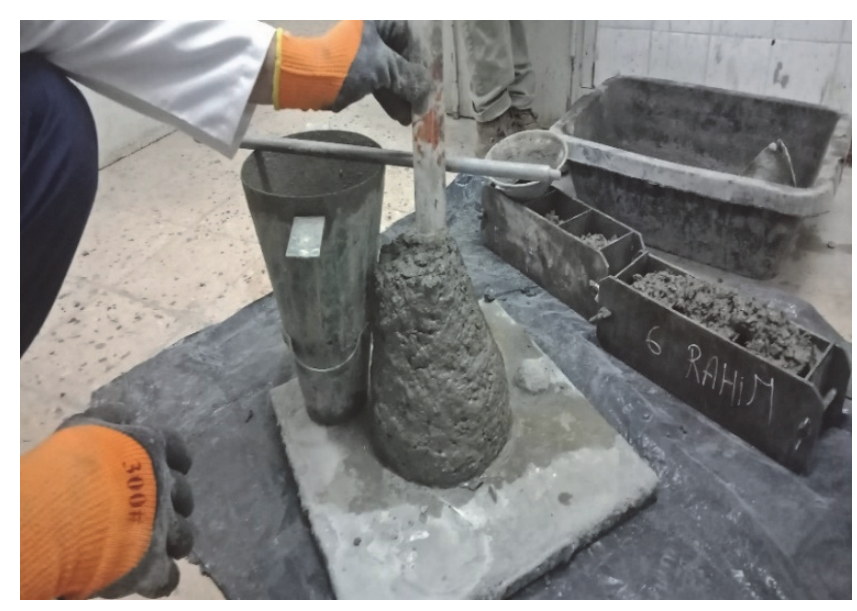

Figure 1: Abrams' cone test.

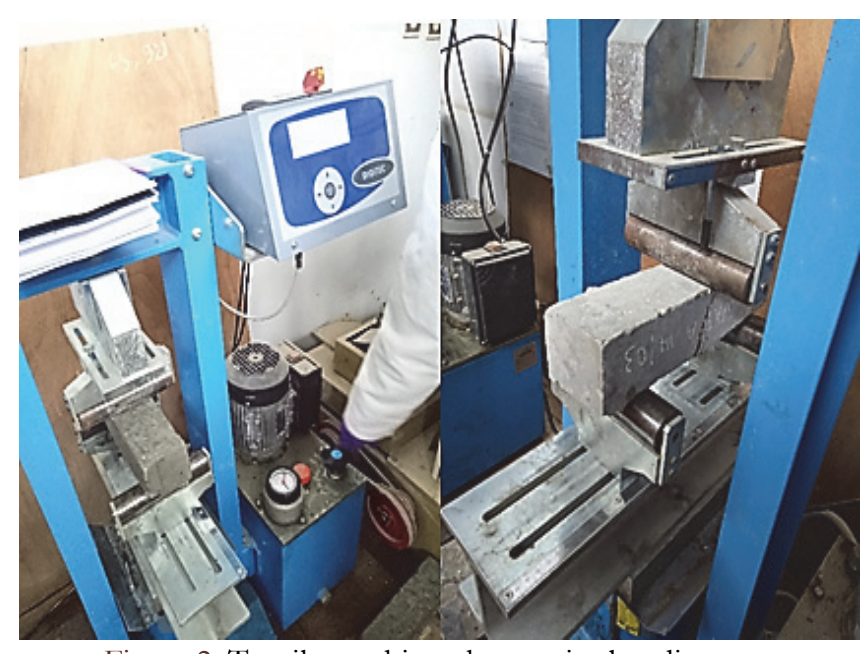

Figure 2: Tensile machine, three point bending test.

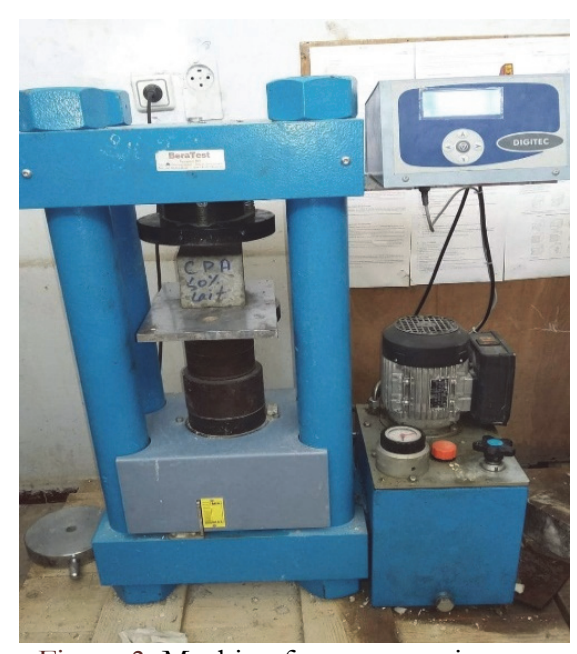

Figure 3: Machine for compression test

The capillarity water absorption test was carried out according to the recommendations of AFPC-AFREM 1997on 360 days cured concrete specimens in the form of discs with $110 \mathrm{~mm}$ in diameter and $50 \mathrm{~mm}$ in height (Fig. 4).

Capillary absorption measures the rate of water absorption by capillary suction of concrete specimens placed in contact with water without hydraulic pressure (Fig. 5). This test consists of following by successive weighing the quantity of water absorbed by a sample previously dried at intervals of $0 \mathrm{~min}, 15 \mathrm{~min}, 30 \mathrm{~min}, 1 \mathrm{~h}, 2 \mathrm{~h}, 4 \mathrm{~h}, 8 \mathrm{~h}$, and $24 \mathrm{~h}$. This allows indirect characterization of capillary porosity.

The absorption coefficient was determined and defined by the following relationship:

$$
C a=\frac{(\mathrm{Mx}-\mathrm{M} 0)}{A}
$$

with:

Ca: absorption coefficient in $\mathrm{kg} / \mathrm{m}^{2}$;

$\mathrm{M}_{\mathrm{x}}$ : mass of the sample after absorption up to constant mass in $\mathrm{kg}$;

$\mathrm{M}_{0}$ : mass of the sample after drying to a constant mass of $105 \pm 5{ }^{\circ} \mathrm{C}$ in $\mathrm{kg}$;

A: area in $\mathrm{m}^{2}$. 


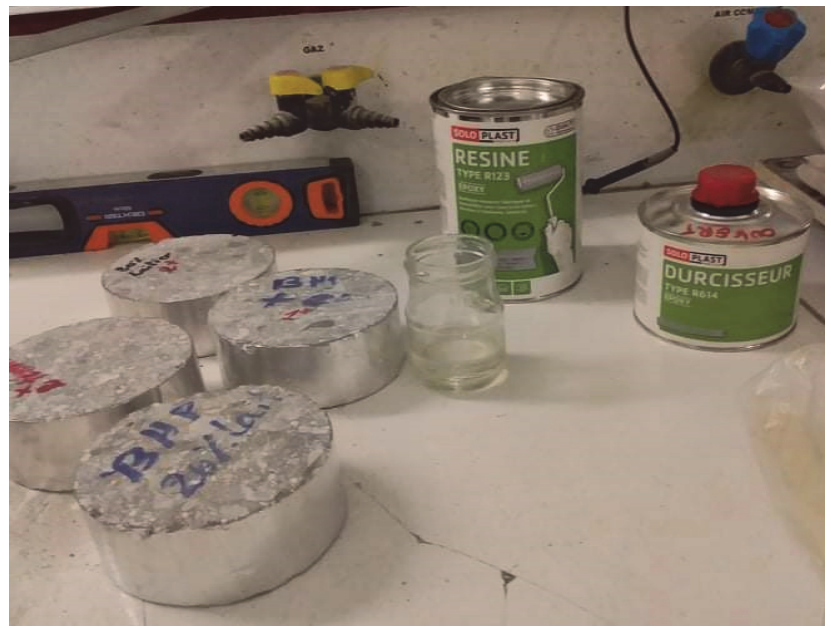

Figure 4: Preparation of specimens for absorption test.

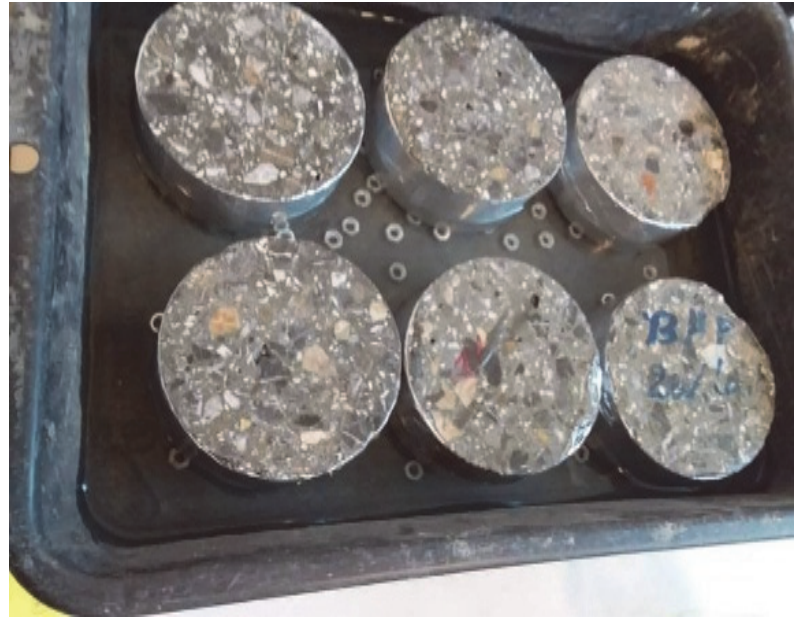

Figure 5: Capillarity water absorption test.

The accessible porosity test was carried out according to standard NF P 18-459 on 360 days cured specimens with 110 mm in diameter and $50 \mathrm{~mm}$ in height (Fig. 6). The principle of this test is to measure the percentage of voids connected with the surface and inside the mass of the concrete. The device measures the porosity accessible to water penetration using a desiccator (Fig. 7). The calculation of the porosity accessible to water is expressed as a volumetric percentage given by the following formula:

$$
P=\frac{\left(M_{\text {air }}-M_{\text {dry }}\right)}{\left(M_{\text {air }}-M_{\text {water }}\right)}
$$

with:

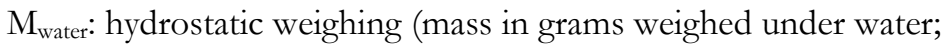
$\mathrm{M}_{\text {air }}$ : weighing in the air of the water-saturated test tube;

$\mathrm{M}_{\text {dry }}$ : weighing in the air of the dry specimen (drying at $\mathrm{T}=105^{\circ} \mathrm{C}$ to constant mass).

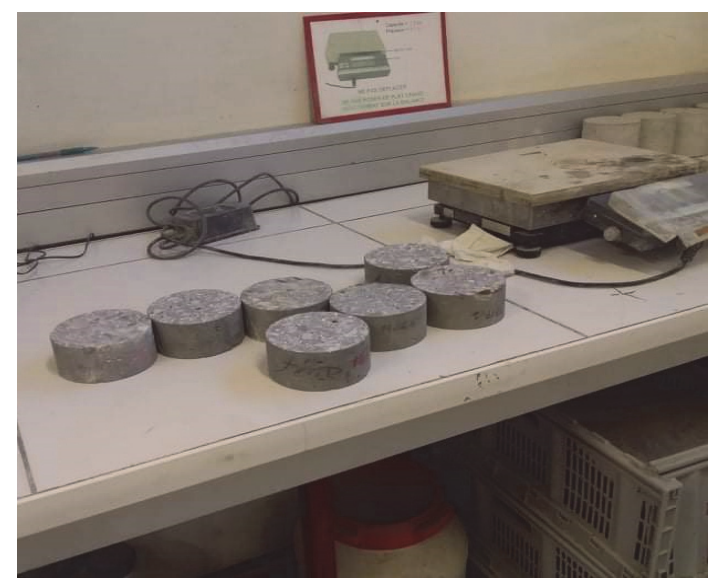

Figure 6: Preparation of specimens for accessible porosity test.

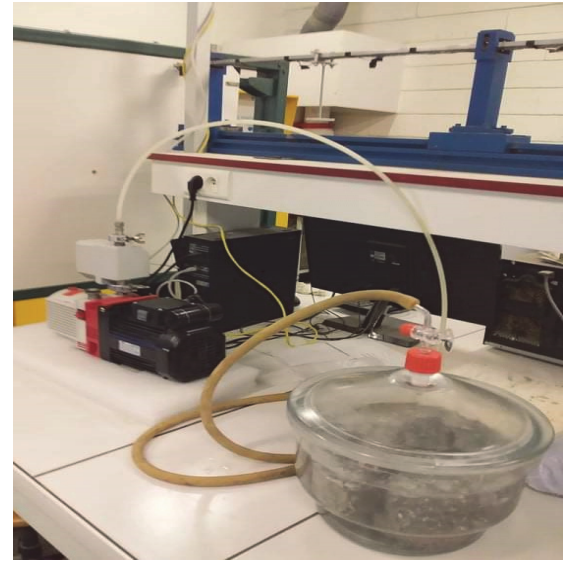

Figure 7: Accessible porosity test protocol.

The gas permeability test was carried out using the CEMBUREAU constant charger with air as percolating neutral gas according to AFPC-AFREM protocol on 360 days cured specimens. The intrinsic permeability of concrete is an important indicator of durability. Darcy's Law describes the viscous laminar flow of a fluid in a porous medium according to a linear relationship between velocity and pressure gradient [25]. The determination of the intrinsic gas permeability consists of performing a linear regression for different points of apparent permeability measured for different applied pressures. The tools used and the experimental protocol for this test are represented in Fig. 8. 


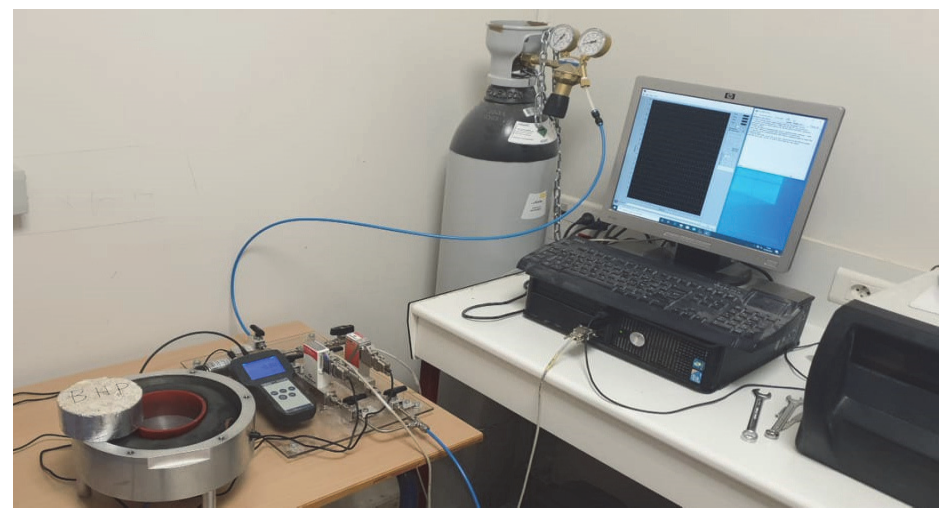

Figure 8: Tools used and experimental protocol for the gas permeability test.

The first step is to prepare cylindrical specimens with $110 \mathrm{~mm}$ in diameter and $50 \mathrm{~mm}$ in height. It is also necessary to check whether the gas cylinder (nitrogen) is open and the gas valve is closed. After that, place the sample with a rubber sleeve to ensure that it is sealed in a cylindrical permeable cell and contact with a grooved metal plate with the same diameter as the sample. The air chamber must be inflated to 8 bar to ensure the radial seal of the sample. To obtain the pressure value (for example: 1bar), wait for the value to stabilize, and then read the flow measurement value on the screen. Repeat this application with pressures of 2 bar, 3 bar and 4 bar. Use the formula of Darcy's Law to determine the apparent permeability for each pressure value:

$$
\operatorname{Kgaz}=\frac{2 \cdot \mathrm{Q} \cdot \mathrm{P}_{\mathrm{atm}} \cdot \mathrm{L} \cdot \mathrm{u}}{\mathrm{A} \cdot\left(\mathrm{P}^{2}-\mathrm{P}_{\mathrm{atm}}^{2}\right)}
$$

with:

Q: Measuring the flow of gas through the specimen;

$\mathrm{P}_{\mathrm{atm}}$ : the outlet atmospheric pressure;

P: the applied inlet pressure;

L: thickness of the test body;

S: section of the test body;

$\mathrm{u}$ : the dynamic viscosity of the gas.

Finally, we can draw the curve of apparent permeability versus back pressure $(1 / \mathrm{P})$. They intercept of the linear curve gives the value of intrinsic permeability.

\section{RESULTS AND DISCUSSION}

The effect of the cement substitution rate by the ground granulated blast furnace slag on the sag test of high performance concretes (workability)

he effect of the cement substitution rate by the ground granulated blast furnace slag in the ternary binder on the workability of HPC was studied by the Abrams' cone test. The results are illustrated in Fig. 9.

Fig. 9 shows that the workability was improved with the increase in the substitution rate of ground granulated blast furnace slag as compared to that of without granulated slag, which exhibits an improvement value of around $10.5 \mathrm{~cm}$. This improvement in workability is very significant for the substitution rates of $20 \%, 30 \%$, and $50 \%$. These are confirmed by most research over the years [37-39]. This increase is mainly due to the morphological state of the ground granulated blast furnace slag which possesses grains with smooth surfaces. 


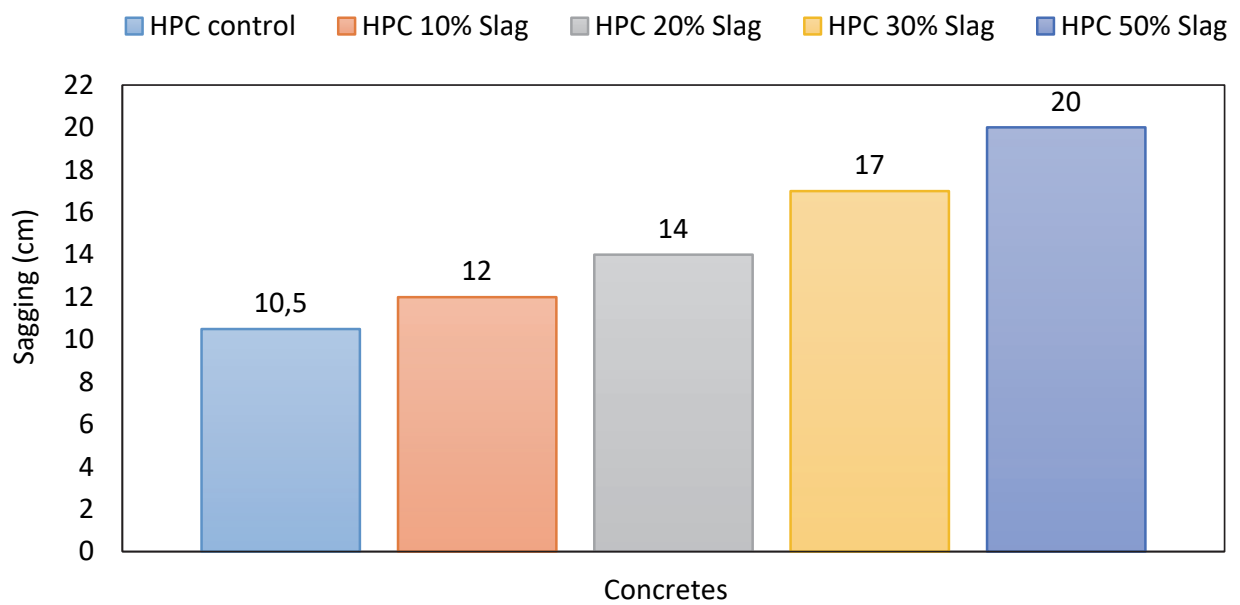

Figure 9: Workability of different HPCs mixes as a function of the substitution rate.

\section{Density in the fresh state}

This measurement was carried out in accordance with NF EN 12350-62012. A container of a known volume was filled entirely with vibrated concrete and then weighed. The effect of the cement substitution rates by the ground granulated blast furnace slag on the density is shown in Fig. 10.

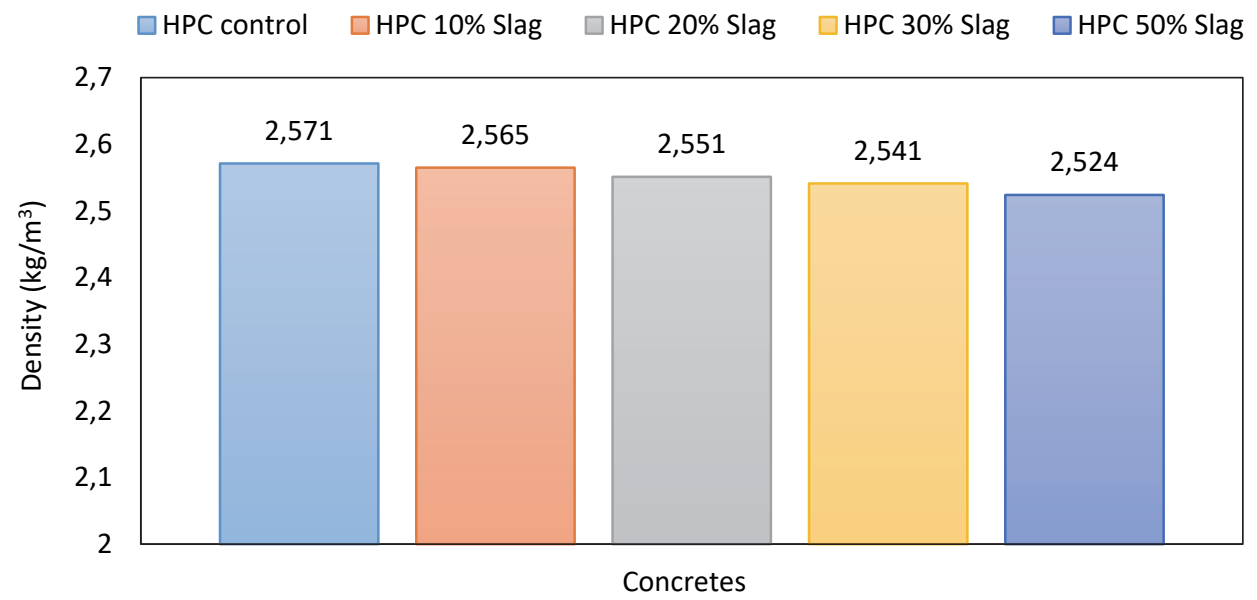

Figure 10: The density of fresh HPCs.

According to Fig. 10 which show the effect of the cement substitution rate with the ground granulated blast furnace slag on the density of the HPC in the fresh state, the density of the control HPC is slightly higher than that of the HPC with the addition of $10 \%, 20 \%, 30 \%$ and $50 \%$ of ground granulated blast furnace slag in partial substitution of cement. This is mainly attributed to the difference between the intrinsic densities of cement and ground granulated blast furnace slag, these confirmed by research work $[38,40]$.

\section{The effect of the cement substitution rate by the ground granulated blast furnace slag on the mechanical behavior of HPCs studied} Tensile strength by three-point bending (at 28 days)

The influence of the rate of substitution of cement by the ground granulated blast furnace slag on the flexural strength was studied by performing the test on prismatic specimens with the dimensions of $7 \times 7 \times 28 \mathrm{~cm}^{3}$. The results are illustrated in Fig. 11.

The analysis of the values obtained for the tensile strength by bending shows the same findings as that of the compression, which is presented below. At short-term, the tensile strength by bending of the control HPC is slightly higher than that of the HPC with $10 \%, 20 \%, 30 \%$, and $50 \%$ substitution of cement with ground granulated blast furnace slag. This is due to 
granular slag is slow in the hydration process preventing the formation of hydration products within 28 days that fill the voids. The results obtained are considered suitable compared to the results obtained on high ultra-performance concretes [41] and high performance concretes [39].

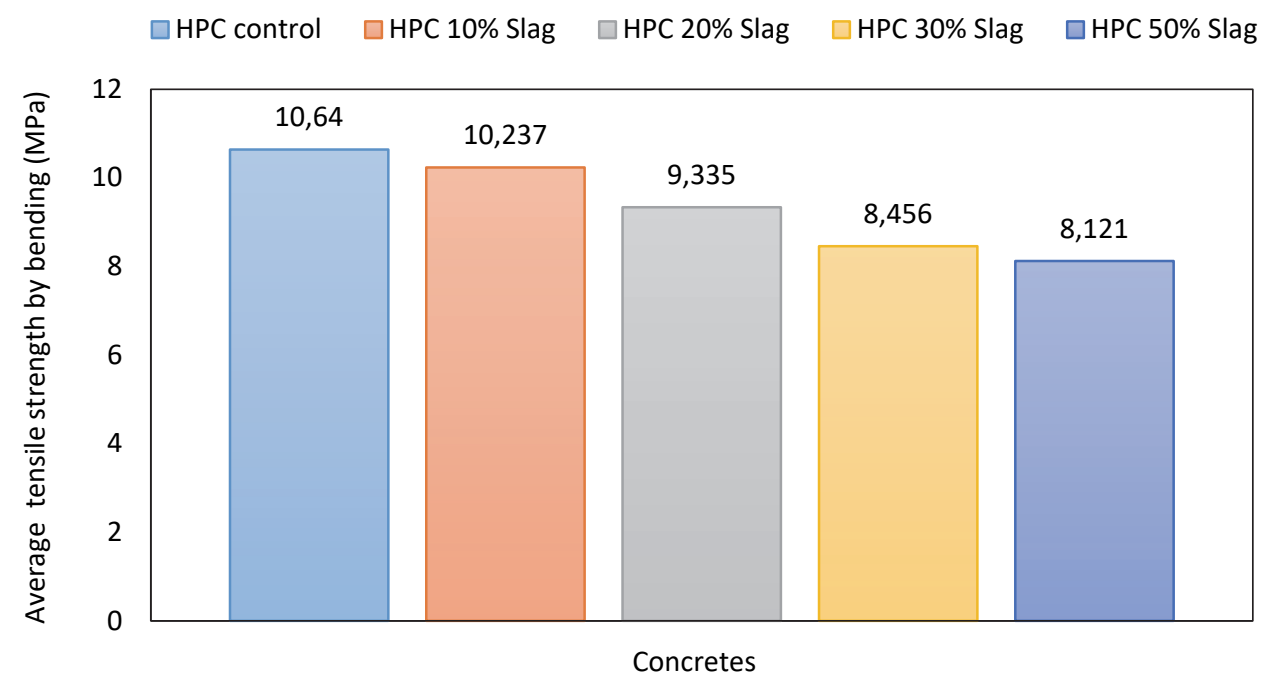

Figure 11: Tensile strength by bending of HPCs at 28 days.

\section{Compressive strength (at $2,7,14,28$, and 360 days)}

The mechanical resistance in the compression test is the main benchmark demonstrating the quality of concrete.

The evolution of the compressive strength for different mix designs of HPCs is shown in Fig. 12.

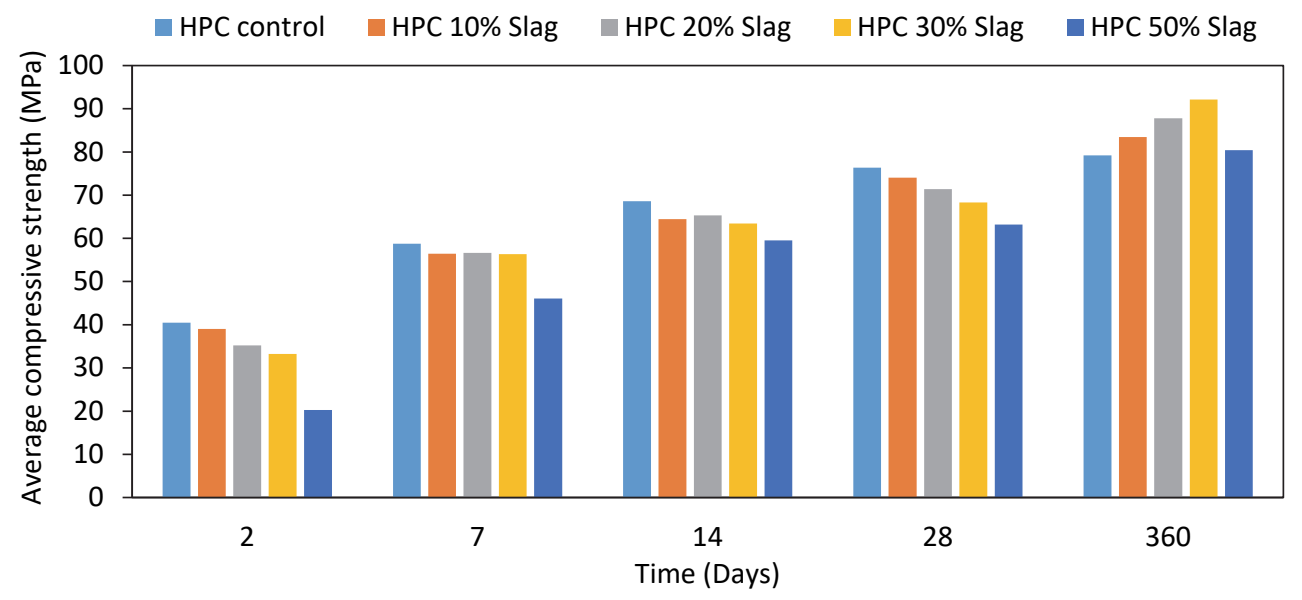

Figure 12: Compressive strength of HPCs at 2, 7, 14, 28, and 360 days.

In the short term and up to 28 days, the compressive strength decrease when the substitution rate increases. A nonsignificant decrease is relatively for HPCs with 10\%, 20\%, and 30\% of ground granulated blast furnace slag and significant for HPC with 50\% as a partial replacement for cement. This is mainly due to the nature of the ground granulated blast furnace slag from the steel plant of El-Hadjar (Annaba, Algeria) which presents in the short term a relatively slow hydraulic reactivity but sufficient to ensure a compressive strength at 28 days greater than $60 \mathrm{MPa}$ required for having an $\mathrm{HPC}$ conforming to the standard as it is observed by several researches [39-41]. In this phase, the Blaine fineness of the slag which is higher than that of the cement fills the tiny voids and accentuates the densification. Furthermore, a remarkable increase in compressive strengths is observed for HPC with the addition of slag in partial substitution of the cement after 360 days of curing, which is greater than those of HPC without the addition of ground granulated blast furnace slag. This is due to the chemical reactions between the portlandite and the silica of the slag with the formation of an additional calcium 
silicate hydrate $(\mathrm{CSH})$ gel and the consumption of lime, which leads to the densification of microstructure and consequently an improvement in the compressive strength [27,38-41].

\section{Durability}

Porosity is the first fundamental factor that affects the durability of concrete and can lead to a loss of structural bearing capacity by influencing the compressive strength and other properties of concrete. The mechanical performance and durability of concrete depend on the porosity. In particular the durability which is associated with the open porosity and more particularly with the interconnected open porosity which allows the penetration of external aggressive agents into the concrete. This porosity promotes the transfer rate by diffusion or by permeability of aggressive chemicals as well as the penetration of gases. For this, the HPCs studied were subjected to tests of water absorption by capillarity, the porosity accessible to water and gas permeability.

In this part, three concrete formulations were tested in the various durability tests: HPC control, HPC $20 \%$ slag and HPC $50 \%$ slag. The choice of $20 \%$ and $50 \%$ in comparison with a control is linked to a compromise between economic and environmental benefits and mechanical performance. A $20 \%$ substitution rate ensures very significant compressive strength at 28 days for a BHP with minimal economic and environmental benefits. On the other hand, the $50 \%$ replacement rate gives us maximum economic and environmental benefits with acceptable resistance.

The porosity accessible to water (at 360 days)

The results of the influence of the cement substitution rate by the ground granulated blast furnace slag on the porosity accessible to water as a function of the density are shown in Fig. 13.

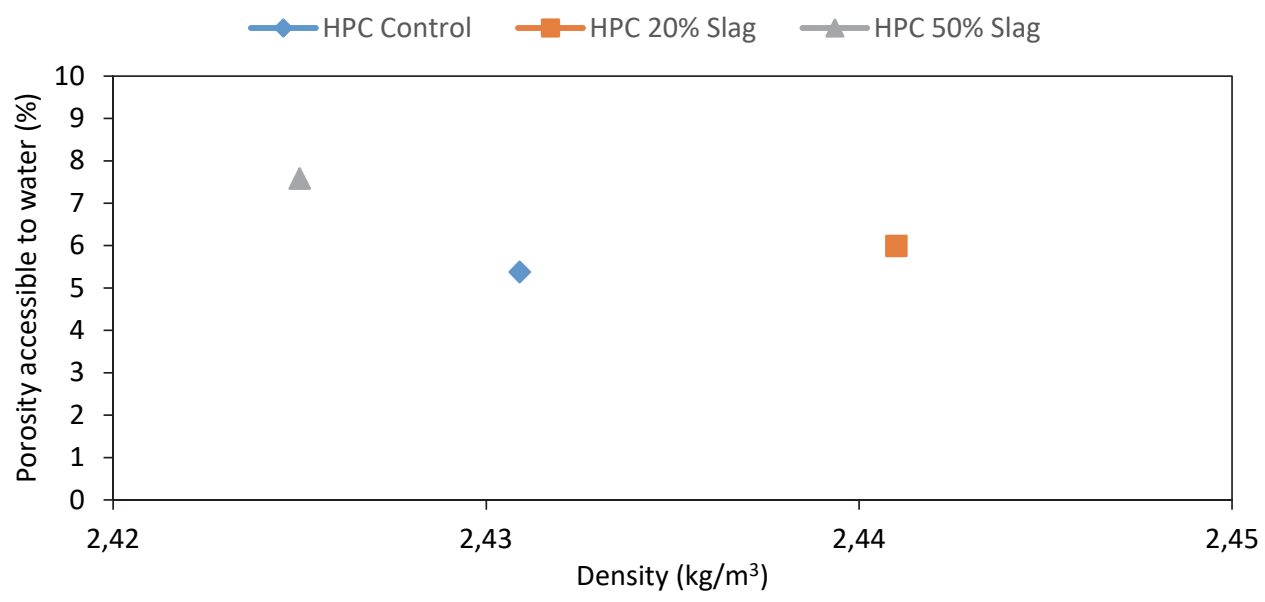

Figure 13: Effect of the cement substitution rate by the ground granulated blast furnace slag on the porosity accessible to water of HPCs at 360 days.

The results indicate that the incorporation of ground granulated blast furnace slag tends to decrease slightly with density and increases the porosity accessible to water for HPC by $50 \%$ cement substitution by the granulated slag compared to control HPC. On the other hand, the density increases slightly and the porosity accessible to water almost equals for HPC with $20 \%$ substitution of cement by the ground granulated blast furnace slag in comparison with control HPC. The pozzolanic activity of ground granulated blast furnace slag is latent over time. The result of the porosity accessible to water for HPC by $50 \%$ substitution of cement by the ground granulated blast furnace slag is better than expected compared to the range of porosity accessible to water in such a concrete context. The study carried out by Tafraoui, [42] shows a porosity accessible to water equal to $6.1 \%$ on samples of ultra-high performance concrete with a water / cement ratio equal to 0.27 . These results are close to those obtained on the samples of HPCs studied [27,38-41].

Capillarity water absorption (at 360 days)

The results of the influence of the cement substitution rate by the ground granulated blast furnace slag on the capillary absorption coefficient of HPC based on ternary binder over time are shown in Fig. 14.

It is clear that the addition of $20 \%$ ground granulated blast furnace slag as partial substitution for cement reduces the capillary absorption coefficient compared to HPC without substitution. This can be explained by the filling effect of slag, which increases the tortuosity of the pore network and therefore makes the transfer of water more difficult. However, the addition of $50 \%$ ground granulated blast furnace slag as a partial replacement for cement results in an increase in the capillary 
absorption coefficient. Nevertheless, this value is considered to be good compared to some research for BHP without substitution of cement by the slag granules in the same region of the materials used as $[38,40]$.

The hydraulic or pozzolanic activities of mineral admixtures promote slower HPC absorption velocity. In fact, the capillary voids surface is covered by $\mathrm{CSH}$ produced during chemical reactions of mineral admixtures. The use of ground granulated blast furnace slag and silica fume mineral admixtures significantly reduces the absorption velocity by improving the porous structure which is appropriate for the results found in the literature $[11,19,24,25]$.

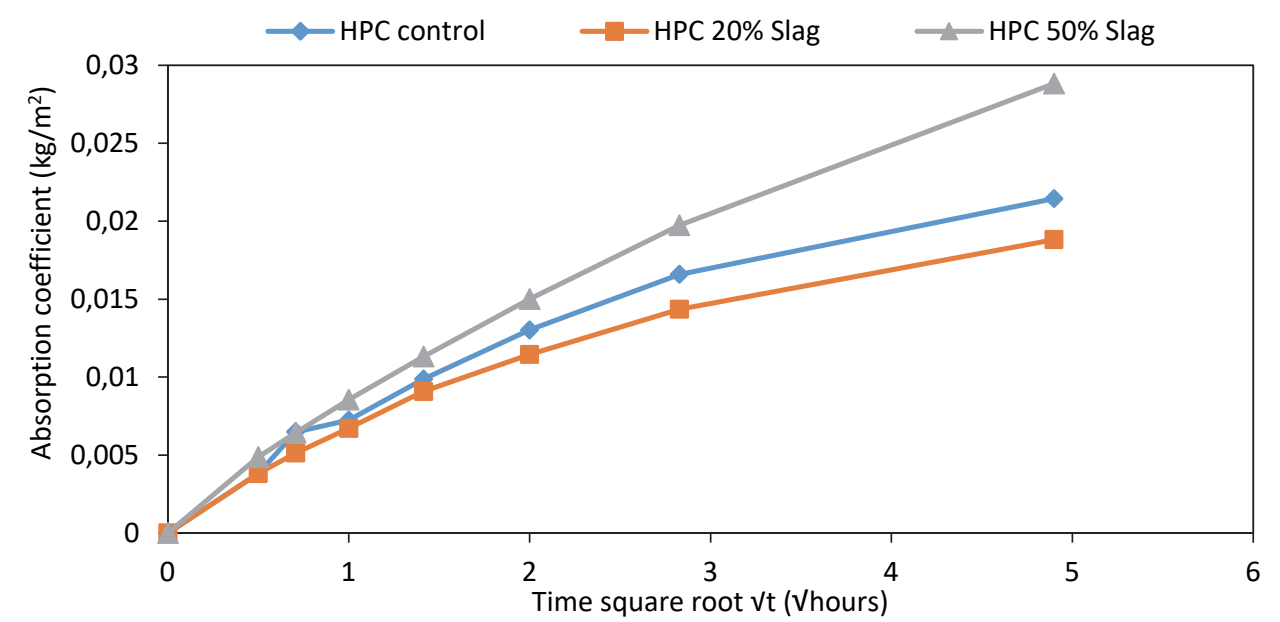

Figure 14: Effect of the cement substitution rate by the ground granulated blast furnace slag on the capillarity water absorption of HPCs at 360 days.

Gas permeability (at 360 days)

The results of the influence of the cement substitution rate by the ground granulated blast furnace slag on the gas permeability of HPBs based on ternary binder are shown in Fig. 15.

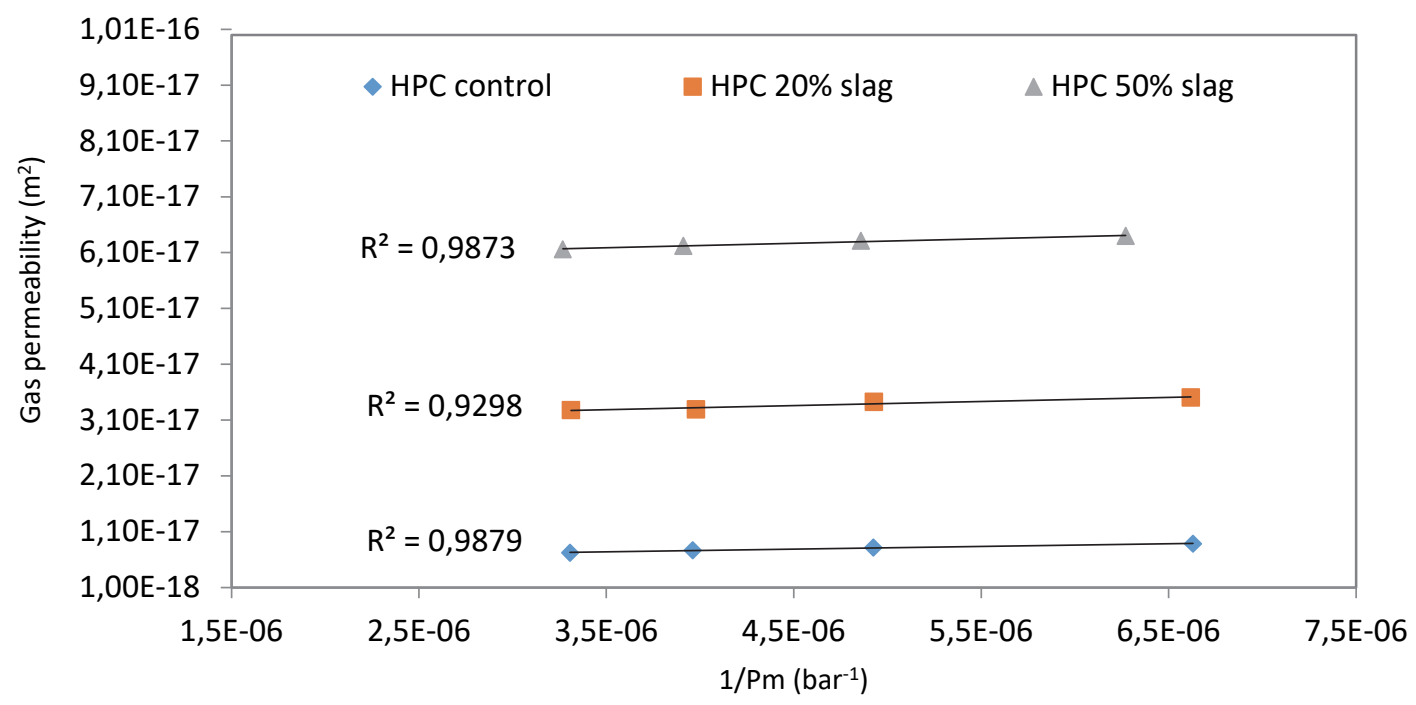

Figure 15: Gas permeability of HPC control, HPC 20\% slag and HPC 50\% slag at 360 days.

The results of the medium-term (360 days) gas permeability of the control and ternary binder based HPC with cement substitution rates by the ground granulated blast furnace slag of the order of $20 \%$ and $50 \%$ are shown in Fig. 15. At this time, the gas permeability recorded for the control HPC is the lowest with an average intrinsic value of the order of 6.83E$18 \mathrm{~m}^{2}$. The HPC based on a ternary binder recorded at this time a slightly higher permeability than that of the control HPC (the values remain comparable). The mean intrinsic permeability values are of the order of $2.81 \mathrm{E}-17 \mathrm{~m}^{2}$ and $5.98 \mathrm{E}-17 \mathrm{~m}^{2}$ 
respectively for $20 \%$ and $50 \%$ replacement of cement by ground granulated blast furnace slag. This difference in permeability can be explained by the low hydraulic reactivity of the Algerian ground granulated blast furnace slag and therefore the period of 360 days of maturation was not sufficient for a good hydration of the studied slag and did not allow the densification of the microstructure necessary for improving permeability. However, for slags with good hydraulic reactivity, a better performance in permeability of concrete slag is reported at 28 and 90 days $[15,16,24,38,40]$. This proves both the low reactivity of the slag studied and the importance of wet curing for improving the durability of slag concretes.

\section{CONCLUSIONS}

I

$\mathrm{n}$ this article, the physical and mechanical properties of HPCs based on ternary binders formulated with granulated slag in partial substitution for cement are presented. We were able to demonstrate the value of replacing cement with granulated slag in the development of high performance concretes. Based on the results obtained, the following conclusions can be drawn:

- Increasing the ground granulated blast furnace slag by 20 to $50 \%$ increased the workability of HPCs. This may be due to the smooth surfaces of the crushed granulated blast furnace slag.

- At early and middle ages (up to 28 days), the addition of ground granulated blast furnace slag causes a decrease in compressive strength. However, after 360 days of curing, blends containing up to $30 \%$ ground granulated blast furnace slag showed an improvement in compressive strength. This is due to the latent hydration reaction of the ground granulated blast furnace slag.

- The experimental results presented in this article confirmed that the addition of granulated blast furnace slag crushed (up to $30 \%$ ) as a substitute for Portland cement can improve physical and mechanical properties of HPC based on ternary binder (cement, silica fume, and granulated blast furnace slag) with a compressive strength equal to $68.32 \mathrm{MPa}$ at 28 days and $92.17 \mathrm{MPa}$ at 360 days. As a result, the substitution up to $50 \%$ of cement is suitable for long-term mechanical properties (compressive strength equal to $80.412 \mathrm{MPa}$ ).

- The use of ground granulated blast furnace slag with a low replacement rate (10 and 30) reduced the porosity of the water. However, the use of $50 \%$ granulated blast furnace slag as a replacement for cement slightly increased the porosity accessible to water.

- The gas permeability coefficient increases with the increase in the replacement rate of crushed granulated slag from blast furnaces. The results obtained on the durability of high performance concrete are acceptable and stimulating compared to previous research of HPCs concrete $[24,38,40,42]$.

- The results obtained show that it is possible to greatly limit the Portland cement content thanks to a granulated slag substitution rate of up to $50 \%$ in the manufacture of a new range of HPCs. This helps to reduce the emission of $\mathrm{CO}_{2}$ into the atmosphere by reducing the energy required for the production of the non-additive cement used in the manufacture of HPCs which is very beneficial for the environment.

\section{ACKNOWLEDGMENTS}

1

he authors would like to thank Dr. Céline BASCOULÈS-PERLOT and the staff of laboratory SIAME- IPRA, EA458 of UPPA University (Anglet, France) who provided facilities for conducting the various durability tests in their laboratory.

\section{REFERENCES}

[1] Toghroli, A., Mehrabi, P., Shariati, M., Trung, N.T., Jahandari, S., Rasekh, H. (2020). Evaluating the use of recycled concrete aggregate and pozzolanic additives in fiber-reinforced pervious concrete with industrial and recycled fibers, Constr. Build. Mater., 252, pp. 118997, DOI: 10.1016/j.conbuildmat.2020.118997.

[2] Afshar, A., Jahandari, S., Rasekh, H., Shariati, M., Afshar, A., Shokrgozar, A. (2020). Corrosion resistance evaluation of rebars with various primers and coatings in concrete modified with different additives, Constr. Build. Mater., 262, pp. 120034, DOI: 10.1016/j.conbuildmat.2020.120034.

[3] Jahandari, S., Saberian, M., Tao, Z., Mojtahedi, S.F., Li, J., Ghasemi, M., Rezvani, S.S., Li, W. (2019). Effects of saturation 
degrees, freezing-thawing, and curing on geotechnical properties of lime and lime-cement concretes, Cold Reg. Sci. Technol., 160, pp. 242-252, DOI: 10.1016/j.coldregions.2019.02.011.

[4] Kazemi, M., Li, J., Lahouti Harehdasht, S., Yousefieh, N., Jahandari, S., Saberian, M. (2020). Non-linear behaviour of concrete beams reinforced with GFRP and CFRP bars grouted in sleeves, Structures, 23, pp. 87-102, DOI: $10.1016 /$ j.istruc.2019.10.013.

[5] Sadeghian, F., Haddad, A., Jahandari, S., Rasekh, H., Ozbakkaloglu, T. (2021). Effects of electrokinetic phenomena on the load-bearing capacity of different steel and concrete piles: A small-scale experimental study, Can. Geotech. J., 58(5), pp. 741-746, DOI: 10.1139/cgj-2019-0650.

[6] Kazemi, M., Hajforoush, M., Talebi, P.K., Daneshfar, M., Shokrgozar, A., Jahandari, S., Saberian, M., Li, J. (2020). Insitu strength estimation of polypropylene fibre reinforced recycled aggregate concrete using Schmidt rebound hammer and point load test, J. Sustain. Cem. Mater., 9(5), pp. 289-306, DOI: 10.1080/21650373.2020.1734983.

[7] Rasekh, H., Joshaghani, A., Jahandari, S., Aslani, F., Ghodrat, M. (2020).Rheology and workability of SCC. SelfCompacting Concrete: Materials, Properties and Applications, Elsevier, pp. 31-63.

[8] Aitcin, P.-C. (2001).Bétons haute performance. Eyrolles, Paris, p. 683.

[9] Lakhal, R., Achoura, D. (2009).Elaboration des bétons à haute performances à base de laitier granulé. 1st International Conference on sustainableBuiltEnvironment Infrastructures in Developing Countries ENSET Oran, Oran, Algeria.

[10] Vejmelková, E., Pavlíková, M., Keršner, Z., Rovnaníková, P., Ondráček, M., Sedlmajer, M., Černý, R. (2009). High performance concrete containing lower slag amount: A complex view of mechanical and durability properties, Constr. Build. Mater., 23(6), pp. 2237-2245, DOI: 10.1016/j.conbuildmat.2008.11.018.

[11] Biskri, Y., Achoura, D., Chelghoum, N., Jauberthie, R. (2016). Effect of mineral admixtures and aggregate natures on the behavior of high performance concrete, J. Mater. Environ. Sci., 7(7), pp. 2617-2628.

[12] Hadj Sadok, A., Foudhil, C.I., Si-Tayeb, S. (2014). Méthode simplifiée de formulation d'un béton à haute performance avec et sans fibre métallique, MATEC Web Conf., 11, pp. 01044, DOI: 10.1051/matecconf/20141101044.

[13] Shi, H. sheng., Xu, B. wan., Zhou, X. chen. (2009). Influence of mineral admixtures on compressive strength, gas permeability and carbonation of high performance concrete, Constr. Build. Mater., 23(5), pp. 1980-1985, DOI: $10.1016 /$ j.conbuildmat.2008.08.021.

[14] Adjoudj, M., Ezziane, K., Kadri, E.H., Ngo, T.T., Kaci, A. (2014). Evaluation of rheological parameters of mortar containing various amounts of mineral addition with polycarboxylate superplasticizer, Constr. Build. Mater., 70, pp. 549-559, DOI: 10.1016/j.conbuildmat.2014.07.111.

[15] Benamara, D., Mezghiche, B. (2010). Vers Un Beton De Haute Performance Elabore De Materiaux Locaux «Bhp», Courr. Du Savoir, 10, pp. 9-14.

[16] Menéndez, G., Bonavetti, V., Irassar, E.F. (2003). Strength development of ternary blended cement with limestone filler and blast-furnace slag, Cem. Concr. Compos., 25(1), pp. 61-67, DOI: 10.1016/S0958-9465(01)00056-7.

[17] Khalifa, N.E.H., Bouasker, M., Mounanga, P., Ben Kahla, N. (2012). Etude du comportement mécanique de liants binaires et ternaires à base de ciment Portland, de laitier de haut fourneau et de filler calcaire, MATEC Web Conf., 2, pp. 01009, DOI: $10.1051 /$ matecconf/20120201009.

[18] Aoual-benslafa, F.K., Semcha, A. (2011). Influence des additions minérales sur la résistance mécanique des mortiers, Afrique Sci. Rev. Int. Des Sci. Technol., 7(2), pp. 16-26.

[19] Kaikea, A., Achoura, D., Duplan, F., Rizzuti, L. (2014). Effect of mineral admixtures and steel fiber volume contents on the behavior of high performance fiber reinforced concrete, Mater. Des., 63, pp. 493-499, DOI: $10.1016 /$ j.matdes.2014.06.066.

[20] Petitpain, M. (2017).Bétons à faible impact environnemental pour l'industrie du béton : accélération du durcissement de bétons à base de liants ternaires. Ph.D. final thesis, Université Lille 1, 2017.

[21] Ali-Boucetta, T., Behim, M., Cassagnabere, F., Mouret, M., Ayat, A., Laifa, W. (2021). Durability of self-compacting concrete containing waste bottle glass and granulated slag, Constr. Build. Mater., 270, pp. 121133, DOI: $10.1016 /$ j.conbuildmat.2020.121133.

[22] Alexandre, J., Jean-Louis, S. (1988). Le Laitier de haut fourneau : élaboration, traitements, propriétés, emplois, Paris.

[23] Zeghichi, L., Mezghiche, B., Merzougui, A. (2007). L'influence de l'activation du laitier sur le comportement mecanique des betons, Leban. Sci. J., 8(2), pp. 105.

[24] Melais, F.Z., Melais, S., Achoura, D., Jauberthie, R. (2015). Valorisation des sous-produits de hauts fourneaux dans la fabrication d'une nouvelle gamme de béton de sable, J. Mater. Environ. Sci., 6(3), pp. 735-742.

[25] Biskri, Y., Achoura, D., Chelghoum, N., Mouret, M. (2017). Mechanical and durability characteristics of High Performance Concrete containing steel slag and crystalized slag as aggregates, Constr. Build. Mater., 150, pp. 167-178, DOI: $10.1016 /$ j.conbuildmat.2017.05.083. 
[26] Kourounis, S., Tsivilis, S., Tsakiridis, P.E., Papadimitriou, G.D., Tsibouki, Z. (2007). Properties and hydration of blended cements with steelmaking slag, Cem. Concr. Res., 37(6), pp. 815-822, DOI: 10.1016/j.cemconres.2007.03.008.

[27] Chaid, R., Molez, L., Sabria, M., Talah, A. (2016). Comportement des BHP de laitier soumis aux cycles immersionséchage Behaviour of slag HPC submitted to immersion-drying cycles, J. Mater. Eng. Struct., 3, pp. $23-33$.

[28] Banfill, P.F.G. (2011). Additivity effects in the rheology of fresh concrete containing water-reducing admixtures, Constr. Build. Mater., 25(6), pp. 2955-2960, DOI: 10.1016/j.conbuildmat.2010.12.001.

[29] Mani, M., Bouali, M.F., Kriker, A., Hima, A. (2021). Experimental characterization of a new sustainable sand concrete in an aggressive environment, Frat. Ed Integrita Strutt., 15(55), pp. 50-64, DOI: 10.3221/IGF-ESIS.55.04.

[30] Papachristoforou, M., Mitsopoulos, V., Stefanidou, M. (2019). Use of by-products for partial replacement of 3D printed concrete constituents; rheology, strength and shrinkage performance, Frat. Ed Integrita Strutt., 13(50), pp. 526-36, DOI: $10.3221 /$ IGF-ESIS.50.44.

[31] Benzerara, M., Guihéneuf, S., Belouettar, R., Perrot, A. (2021). Combined and synergic effect of algerian natural fibres and biopolymers on the reinforcement of extruded raw earth, Constr. Build. Mater., 289, pp. 123211, DOI: $10.1016 /$ j.conbuildmat.2021.123211.

[32] Melais, F.Z., Achoura, D., Ghorbel, E. (2021). Durability of mortars containing blast furnace slags used as a partial substitute of Portland cement exposed to external sulfate attacks, 12(6), pp. 837-852.

[33] Melais, S., Bouali, M.F., Melaikia, A., Amirat, A. (2021). Effects of coarse sand dosage on the physic-mechanical behavior of sand concrete, Frat. Ed Integrita Strutt., 15(56), pp. 151-159, DOI: 10.3221/IGF-ESIS.56.12.

[34] Benyahia, A., Choucha, S., Ghrici, M., Omran, A. (2018). Influence of limestone dust and natural pozzolan on engineering properties of self-compacting repair mortars, Frat. Ed Integrita Strutt., 12(45), pp. 135-146, DOI: 10.3221 /IGF-ESIS.45.11.

[35] Jadidi, A., Amiri, M., Zeighami, E. (2017). Experimental evaluation of steel fiber effect on mechanical properties of steel fiber-reinforced cement matrix, Frat. Ed Integrita Strutt., 11(42), pp. 249-262, DOI: 10.3221/IGF-ESIS.42.27.

[36] Boudina, T., Benamara, D., Zaitri, R. (2021). Optimization of high-performance-concrete properties containing fine recycled aggregates using mixture design modeling, Frat. Ed Integrita Strutt., 15(57), pp. 50-62, DOI: 10.3221/IGF-ESIS.57.05.

[37] Manai, K. (1995).Étude de l'effet d'ajouts chimiques et minéraux sur la maniabilité, la stabilité et les performances des bétons autonivelants. Ph.D. final thesis, Université de Sherbrooke, Canada.

[38] Kaiikea, A. (2015).Elaboration des bétons à hautes performances fibrés avec addition du laitier granulé (comportement mécanique et durabilité. Ph.D. final thesis, Université Badji Mokhtar Annaba, Algeria.

[39] Abdelli, K. (2010).Influence des laitiers sur la microstructure des bétons a l'état frais et durci. Ph.D. final thesis, Université des Sciences et de la Technologie Houari Boumediene USTHB, Algeria.

[40] Biskri, Y. (2017).Comportement physico-mécanique et durabilité des bétons à hautes performances à base de deux influence de la nature des granulats. Ph.D. final thesis, Université Badji Mokhtar Annaba, Algeria.

[41] Zenati, A. (2014).Formulation des bétons à ultra hautes performances à base d'ajouts cimentaires. Ph.D. final thesis, Université des Sciences et de la Technologie Houari Boumediene USTHB, Algeria.

[42] Tafraoui, A. (2009).Contribution à la valorisation du sable de dune de l'erg occidental (Algérie). Ph.D. final thesis, I.N.S.A. de Toulouse, France. 